Article

\title{
Interpretation US Elastography in Chronic Hepatitis B with or without Anti-HBV Therapy
}

\author{
Cheng-Han Lee ${ }^{1}$, Yung-Liang Wan ${ }^{2,3}$, Tse-Hwa Hsu ${ }^{1}$, Shiu-Feng Huang ${ }^{4}$, Ming-Chin Yu ${ }^{5}$, \\ Wei-Chen Lee ${ }^{6}$, Po-Hsiang Tsui ${ }^{3}$, Yi-Cheng Chen ${ }^{1}$, Chun-Yen Lin ${ }^{1}$ id and Dar-In Tai ${ }^{1, *}$ (iD \\ 1 Department of Gastroenterology and Hepatology, Chang Gung Memorial Hospital, Taipei 105, Taiwan; \\ b9102011@cgmh.org.tw (C.-H.L.); echohsuth45@cgmh.org.tw (T.-H.H.); yicheng@cgmh.org.tw (Y.-C.C.); \\ chunyenlin@gmail.com (C.-Y.L.) \\ 2 Department of Medical imaging and Intervention, Chang Gung Memorial Hospital, Taoyuan 333, Taiwan; \\ ylw0518@cgmh.org.tw \\ 3 Department of Medical imaging and Radiological Sciences, College of Medicine, Institute for Radiological \\ Research, Chang Gung University, Taoyuan 333, Taiwan; tsuiph@mail.cgu.edu.tw \\ 4 Division of Molecular and Genomic Medicine, National Health Research Institute, Taipei 115, Taiwan; \\ sfhuang@nhri.org.tw \\ 5 Department of General Surgery, Chang Gung Memorial Hospital, Taoyuan 333, Taiwan; \\ a75159@cgmh.org.tw \\ 6 Department of Liver and Transplantation Surgery, Chang Gung Memorial Hospital, Taoyuan 333, Taiwan; \\ weichen@cgmh.org.tw \\ * Correspondence: tai48978@cgmh.org.tw; Tel.: +886-3328-1200 (ext. 8107)
}

Received: 15 September 2017; Accepted: 30 October 2017; Published: 13 November 2017

\begin{abstract}
Inflammation has significant impacts on liver fibrosis measurement by ultrasound elastography. The interpretation requires further optimization in patients with or without anti-viral therapy. We prospectively enrolled a consecutive series of patients with chronic hepatitis B who received liver histology analysis and acoustic radiation force impulse (ARFI). 146 patients who underwent liver biopsy $(50.9 \%)$ or tumor resection $(49.1 \%)$ were enrolled. 34 patients $(23.3 \%)$ had been receiving anti-hepatitis B therapy of various duration. The areas under the receiver-operating characteristic (AUROC) for the diagnosis of Metavir F4 by mean ARFI was 0.820 in the non-treatment group and 0.796 in the treatment group. The ARFI tended to be not lower $(100 \%)$ than the corresponding Metavir grading in patients with treatment within 12 months, equal (75\%) from 13 to 31 months, and lower (71.4\%) after 32 months. We conclude that ARFI is a reliable tool for measurement of liver fibrosis in chronic hepatitis B patients with ALT (alanine aminotransferase) $<5 \mathrm{x}$ the upper limit of normal. For those patients under anti-HBV therapy, the optimal timing for ARFI analysis will be over 1-2.5 years of nucleos(t)ide analogue therapy. The ARFI measurement after 2.5 years tends to be lower than the corresponding histology grading.
\end{abstract}

Keywords: acoustic radiation force impulse; chronic hepatitis B; liver cirrhosis; anti-HBV therapy

\section{Introduction}

Liver cirrhosis is the major risk factor for mortality in chronic hepatitis B carriers [1,2]. The annual rate of progression from chronic hepatitis to cirrhosis is $2-5 \%$ in hepatitis $B$ e antigen-positive and $3-10 \%$ in e antigen-negative patients [3,4]. Patients with absent or low-grade fibrosis at diagnosis are thought to have a relatively lower risk of progression to cirrhosis in 20 years [5]. The diagnosis and further therapeutic decision usually relies on the fibrosis severity, so an accurate assessment is crucial to treatment outcomes. It is easy to diagnose cirrhosis by liver ultrasound [1,2]—what is more difficult is assessing more subtle degrees of fibrosis. Liver biopsy is considered the gold standard for liver fibrosis assessment; however, it is an invasive procedure with rare, but serious complications 
(mortality rate $<0.01 \%$ ) [6]. Sampling error and intra- or inter-observer variability also affect the diagnostic consistency [7]. Elastography, either by transient elastography or acoustic radiation force impulse (ARFI), is a promising, non-invasive modality for the diagnosis of liver fibrosis [8-11]. It can be performed in a periodic follow-up and is generally superior to other serological modalities [12-14]. In a meta-analysis study, ARFI demonstrated a satisfactory ability to predict higher-stage liver fibrosis $(\mathrm{F}=3)$ and liver cirrhosis $(\mathrm{F}=4)[15]$. However, inflammation, variation, and other factors have significant impacts on the interpretation [16-22]. In our previous study as well as in others, ARFI had a poorer performance in the measurement of liver fibrosis in chronic hepatitis $\mathrm{B}$ than in chronic hepatitis C [16]. How to make interpretation of liver fibrosis during anti-HBV therapy is unclear. To improve the interpretation of ARFI in chronic hepatitis B patients with or without anti-HBV therapy, we conducted a replication study using two-location measurements and limited the operator to one well-trained technician.

\section{Materials and Methods}

\subsection{Study Design and Subjects}

A consecutive series of patients with liver diseases who received liver biopsy or segmental hepatectomy at Chang Gung Memorial Hospital, Linkou Medical Centre from January 2014 to December 2016 were enrolled prospectively.

We included all patients who were seropositive for hepatitis B surface antigen and age greater than 18-year-old in this study. The following patients were excluded: (i) those co-infected with hepatitis $C$ virus or human immunodeficiency virus (HIV) infection, or presenting autoimmune or alcoholic liver disease; (ii) those with liver cirrhosis, functional classification Child B or C; (iii) those with a liver tumor greater than $5 \mathrm{~cm}$ in the R hepatic lobe, which makes ARFI unable to select a suitable location for measurement, and (iv) those who refused to sign an inform consent form.

All of the patients from the outpatient department received ARFI on the day of the liver biopsy. For those hospitalized patients planning to receive surgery for tumor resection, ARFI was performed within one month before the surgery.

This study was approved by the Institute Review Board of Chang Gung Memorial Hospital (IRB: 104-2353C). Written Informed consent was obtained from all participants before the start of the study.

\subsection{Laboratory Assessments}

Blood samples were obtained under fasting conditions. Liver biochemistry, the international normalized ratio (INR) of prothrombin time (PT), and a hemogram were measured using commercially available kits and automatic analyzers. HBsAg and anti-HCV were tested with an enzyme immunoassay (Abbott Diagnostics). The entire study was conducted in the clinical laboratory of this hospital, a laboratory certified by The College of American Pathologists.

\subsection{Serology Tests for Fibrosis}

The aspartate to platelet ratio index (APRI) [23] and the fibrosis-4 score (FIB4) [24] are used as non-invasive serology methods to measure liver fibrosis. The APRI was calculated using the formula: (Aspartate Aminotransferase (AST) [U/L]/upper limit of normal [U/L]) $\times(100 /$ platelet [109/L]).

The FIB-4 values were calculated using the formula: age (years) $\times$ AST [U/L]/(platelets [109/L] $\times$ Alanine Aminotransferase (ALT) [U/L]) $1 / 2$ ).

\subsection{Histological Assessment}

Each patient from the outpatient department was initially screened by hemogram, prothrombin time, and blood biochemistry to ensure that there was no contraindication for liver biopsies. US-guided percutaneous liver biopsy was performed using an 18-gauge biopsy core needle with an automatic pistol device (Bard Magnum, Bard Peripheral Vascular Inc., Tempe, AZ, USA). For patients who 
had received surgical resection, the resected non-tumor part was used for liver fibrosis assessment. The tissue samples were fixed with formalin and embedded with paraffin, and 4- $\mu \mathrm{m}$-thick sections were stained with hematoxylin and eosin (H\&E) and reticulin silver (Masson trichome method). Histology was evaluated by an experienced pathologist (S.-F.H.) who was unaware of the ARFI study. Liver fibrosis stages were evaluated semi-quantitatively according to the Metavir scoring system [25]. Necroinflammatory activity was graded according to the modified histological activity index grading system (Ishak) in 4 categories: A for periportal or periseptal interface hepatitis; B for confluent necrosis; $\mathrm{C}$ for focal lytic necrosis, apoptosis, and focal inflammation; and D for portal inflammation with a maximal score of 18 [26].

\subsection{ARFI Imaging Study}

ARFI imaging was mainly carried out with Acuson S2000 (Siemens Healthcare, Erlangen, Germany) and Virtual Touch tissue quantification software (Siemens Healthcare). The study protocol was generally according to the guideline with some modification [27]. Most of the examinations were conducted by one experienced technician (H.-T.W.). On a few occasions, the study was conducted by experienced hepatologists (D.-I.T. or Y.-C.C.). They were unaware of the patients' histology during ARFI measurements. The patients remained supine with the right arm extended above the head during the scan. All of the patients received ARFI measurements from the right intercostal space. We selected two locations separated by one intercostal space featuring optimal real-time ultrasonography with liver tissue having no large blood vessels [16]. Location A targeted the right lower liver, while Location $\mathrm{B}$ targeted the right upper liver. During the measuring process, the area of interest was maintained at a vertical angle to the skin. A measurement with a depth of $3-6 \mathrm{~cm}$ beneath the skin was chosen to standardize the examination. Most patients were asked to maintain a normal, slow breath during the measurement. In patients with rapid breathing, temporary holding of the breath during the measurement was requested. Valsalva Maneuver, which causes reduction of hepatic venous blood flow may decrease liver stiffness. No patients encountered failure of assessment for shortness of breathing. At least 10 measurements were obtained for each location. Liver stiffness measurements were considered valid only if 10 successful acquisitions were obtained, and the interquartile range (IQR) to median ratio of the 10 acquisitions was $<0.25$. When data from two locations had a difference greater than $0.2 \mathrm{~m} / \mathrm{sec}$, repeat measurements were taken to confirm the study [28].

\subsection{FibroScan}

A FibroScan 502 touch machine (Echosens ${ }^{\circledR}$, Paris, France) has been available in our hospital since July 2016. Both ARFI and transient elastography were done at the same time to all patients enrolled in the last 6 months of the study. M probe was used for measurement in all of the patients. For those patients with a body mass index greater than 28 , an extra large (XL) probe was performed. All procedures were performed by a well-trained technician according to the relevant manufacturers.

\subsection{Statistics}

Patient characteristics were expressed as the number and percentage or mean \pm standard deviation (SD) as appropriate. Continuous variables of two independent groups were compared with a Student's t-test or Mann-Whitney U test depending on the distribution. Categorical variables were tested using the chi-square test or Fisher's exact test, as applicable. The receiver-operating characteristic (ROC) curves and areas under the ROC (AUROC) were calculated for evaluation of the best prediction tests for histology proven liver cirrhosis. All statistical analyses were performed using SPSS (version 11.5; SPSS Inc., Chicago, IL, USA) or Interactive Chi-square Test to calculate the difference between groups (Preacher, KJ. Calculation for the chi-square test: An interactive calculation tool for chi-square tests of goodness of fit and independence, http: / / quantpsy.org). A $p$ value of $<0.05$ was considered to indicate statistical significance. 
The case numbers needed for AUROC analysis to reach type I error 0.05 and type II error (1-power) 0.20 was calculated by MedCalc-version 16.8 (MedCalc Software bvba, Oostende, Belgium). When the AUROC curve is expected to be 0.8 and null hypothesis value is 0.5 , the minimal case numbers needed to achieve statistic power 0.8 will be around 27 cases.

\section{Results}

\subsection{Patient Demographics}

A total of 146 patients with chronic hepatitis B were enrolled. The demographic characteristics are shown in Table 1 . Seventy-four (50.9\%) patients underwent liver needle biopsy and seventy-two patients $(49.1 \%)$ received liver tumor resection. Thirty-four patients $(23.3 \%)$ had been receiving anti-HBV therapy of varying duration at the time of enrollment. The mean age of all patients was $53.0 \pm 10.7$ years. The male gender was predominant in both groups $(82.4 \%$ in treatment group vs. $75.9 \%$ in non-treatment). The treatment group had a lower platelet count $\left(161.62 \times 10^{9} / \mathrm{L}\right.$ vs. $\left.187.33 \times 10^{9} / \mathrm{L}, p=0.034\right)$, a lower Ishak's inflammation score (2.76 vs. 3.89, $\left.p=0.020\right)$, and a higher ultrasound fibrosis score ( 7.26 vs. $6.43, p=0.001)$ than the non-treatment group Twenty-four patients $(21.4 \%)$ in the non-treatment group and 14 patients $(41.2 \%)$ in the treatment group had histologically proven liver cirrhosis (Metavir fibrosis score $=4$ ).

Table 1. Demographic and laboratory data with or without anti-HBV therapy.

\begin{tabular}{|c|c|c|c|}
\hline Category & Non-Treatment & Treatment & $p$ Value \# \\
\hline Total No & 112 & 34 & \\
\hline Age (year) & $52.34 \pm 10.80$ & $55.05 \pm 10.41$ & \\
\hline Male (\%) & $85(75.9)$ & $28(82.4)$ & \\
\hline Liver cancer $(\%)$ & $55(49.1)$ & $19(55.9)$ & \\
\hline Ultrasound spleen index $\left(\mathrm{cm}^{2}\right)$ & $16.58 \pm 7.10$ & $16.84 \pm 5.80$ & \\
\hline Ultrasound fibrosis score & $6.43 \pm 1.38$ & $7.26 \pm 1.05$ & 0.001 \\
\hline GGT (glutamyl transpetidase) (U/L) & $60.9 \pm 71.68$ & $56.48 \pm 53.90$ & \\
\hline AST $(\mathrm{U} / \mathrm{L})$ & $73 \pm 111$ & $49 \pm 48$ & \\
\hline $\operatorname{ALT}(\mathrm{U} / \mathrm{L})$ & $92 \pm 193$ & $56 \pm 75$ & \\
\hline Bilirubin (mg/DL) & $0.97 \pm 1.22$ & $0.76 \pm 0.36$ & \\
\hline Platelet $\left(10^{9} / \mathrm{L}\right)$ & $187.33 \pm 65.10$ & $161.62 \pm 47.52$ & 0.034 \\
\hline Prothrombin time $\left({ }^{*}\right.$ INR) & $1.07 \pm 0.08$ & $1.08 \pm 0.06$ & \\
\hline Body height $(\mathrm{cm})$ & $164.56 \pm 7.51$ & $164.81 \pm 10.47$ & \\
\hline Body weight (kg) & $69.38 \pm 10.47$ & $69.45 \pm 13.30$ & \\
\hline \multicolumn{4}{|l|}{ Histology } \\
\hline Ishak inflammatory score & $3.89 \pm 2.45$ & $2.76 \pm 1.74$ & 0.020 \\
\hline Confluence necrosis (No.) & $3(2.7)$ & $1(2.9)$ & \\
\hline Metavir fibrosis score 0 & $3(2.7)$ & $0(0)$ & \\
\hline Metavir fibrosis score 1 & $12(10.7)$ & $2(5.9)$ & \\
\hline Metavir fibrosis score 2 & $43(38.4)$ & $5(14.7)$ & \\
\hline Metavir fibrosis score 3 & $30(26.8)$ & $13(38.2)$ & \\
\hline Metavir fibrosis score 4 & $24(21.4)$ & $14(41.2)$ & 0.026 \\
\hline
\end{tabular}

Number in the parenthesis is percentage of total cases. * INR = international normalized ratio; \# Univariate analysis, not significant after multivariate analysis.

\subsection{Sensitivity and Specificity of ARFI Measurements}

Data on ARFI were successfully obtained by two-location measurements from all patients. The diagnostic performance of ARFI and serum fibrosis markers for liver fibrosis was assessed using ROC curves. According to the data on two-location measurements, ARFI values measured at Location A or B, mean values of Locations A and B, and higher or lower ARFI data between Locations A and B were examined separately. 
For comparison with ARFI parameters, data on APRI and FIB4 were combined in the ROC curve analysis. The results are listed in Figure 1 for patients without anti-HBV therapy and in Figure 2 for patients with anti-HBV therapy. The ARFI-related parameters have significantly higher area under the ROC (AUROC) curve than APRI or FIB4 in both treatment and non-treatment groups.

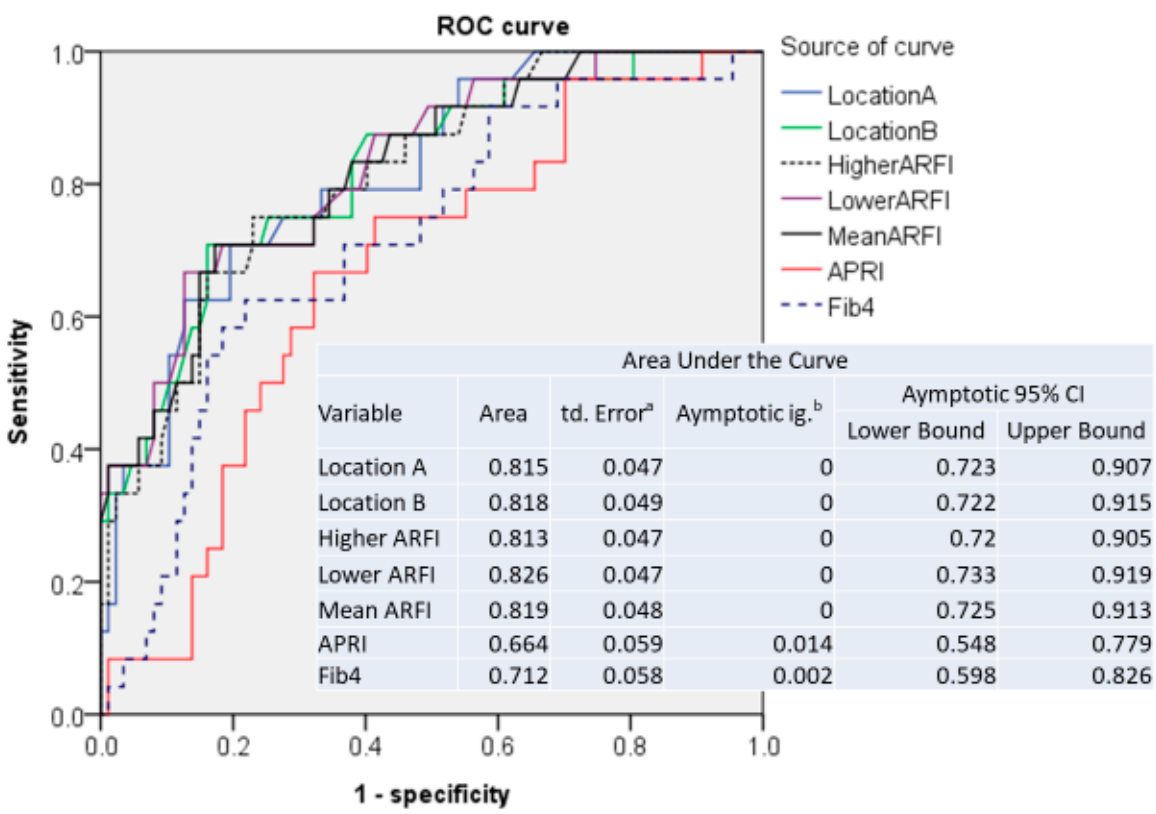

Figure 1. The areas under the receiver-operating characteristic (AUROC) of acoustic radiation force impulse (ARFI) values, APRI, and fibrosis-4 score (FIB4) for prediction of liver cirrhosis in patients with chronic hepatitis B without anti-HBV therapy. A higher AUROC is found in ARFI-related parameters (0.813 0.826) than in APRI (0.664) or FIB4 (0.712) (Aymptotic 95\% CI: Asymptotic 95\% Confidence

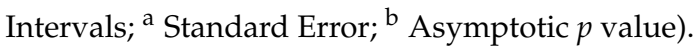

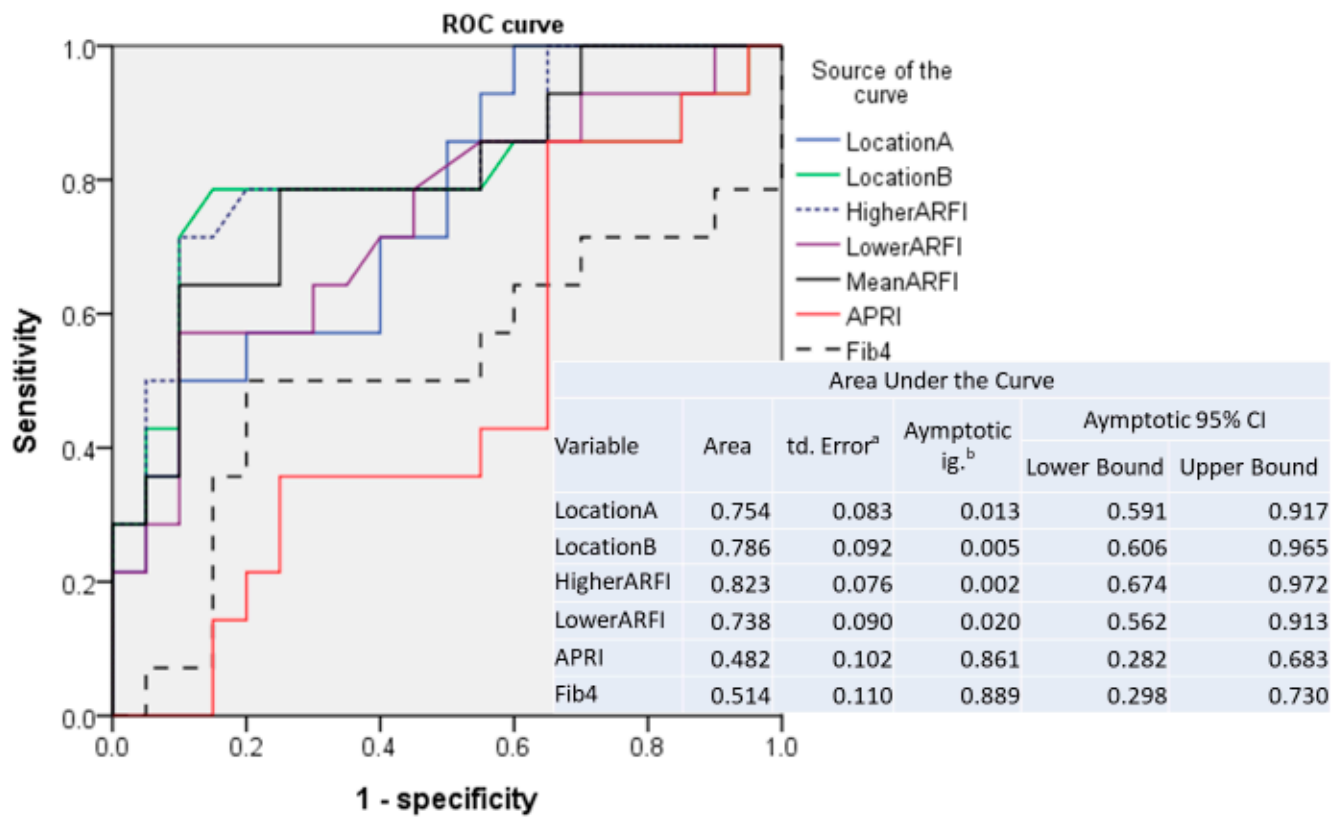

Figure 2. The AUROC of ARFI values, APRI, and FIB4 for prediction of liver cirrhosis in patients with chronic hepatitis B with anti-HBV therapy. A higher AUROC is found in ARFI-related parameters (0.737 0.823) than in APRI (0.482) or FIB4 (0.514) (Aymptotic 95\% CI: Asymptotic 95\% Confidence Intervals; ${ }^{\text {a Standard Error; }}{ }^{\mathrm{b}}$ Asymptotic $p$ value). 
According to the results of AUROC analysis, the cut-off values for the prediction of liver cirrhosis on each parameter are listed in Table 2. Among the ARFI parameters, lower ARFI shows the highest AUROC curve (0.827) in non-treatment groups, whereas higher ARFI shows the highest AUROC curve (0.823) in the treatment group. To simplify the cut-off system, we use mean ARFI in both treatment and non-treatment groups.

The AUROC for the diagnosis of Metavir F4 by mean ARFI is 0.820 [standard error of mean (SE) 0.048, (confidence intervals (CI): 0.725; 0.913) Figure 1] in the non-treatment group. The cut-off value for the prediction of liver cirrhosis (Metavir F4) by mean ARFI is $1.523 \mathrm{~m} / \mathrm{sec}$ with a sensitivity of 0.708 and a specificity of 0.830 in the non-treatment group (Table 2). Since inflammation has a significant impact on ARFI value, AUROC was performed on 99 patients with an ALT level lower than 5x upper limit normal (ULN). The cut-off values remain almost the same (1.523) with increasing sensitivity (0.696) and specificity (0.829). When only the 79 patients with an ALT level lower than 2x ULN were included, the AUROC showed a similar cut-off value (1.523) without a significant improvement in sensitivity and specificity as compared with those patients with an ALT lower than 5x ULN.

The AUROC for the diagnosis of Metavir F4 by mean ARFI is 0.796 [SE 0.080, (CI: 0.641; 0.952) Figure 2] in the treatment group. The cut-off value of mean ARFI for diagnosis of liver cirrhosis was $1.420 \mathrm{~m} / \mathrm{sec}$ with a sensitivity of 0.786 and a specificity of 0.750 in the treatment group (Table 2).

Table 2. Cut-off values in different ARFI measurements for Metavir 4 in patients with difference inflammation.

\begin{tabular}{|c|c|c|c|c|}
\hline Type of ARFI & AUROC & Cut-Off (m/sec) & Sensitivity & 1-Specificity \\
\hline \multicolumn{5}{|c|}{ Patients without anti-HBV treatment $(\mathrm{N}=112)$} \\
\hline Location A & 0.816 & 1.505 & 0.708 & 0.193 \\
\hline Location B & 0.818 & 1.515 & 0.708 & 0.159 \\
\hline Higher & 0.813 & 1.515 & 0.750 & 0.227 \\
\hline Lower & 0.827 & 1.460 & 0.708 & 0.182 \\
\hline Mean & 0.820 & 1.523 & 0.708 & 0.170 \\
\hline \multicolumn{5}{|c|}{ Patients without anti-HBV treatment and ALT level <5x ULN (N = 99) } \\
\hline Location A & 0.816 & 1.415 & 0.739 & 0.263 \\
\hline Location B & 0.815 & 1.460 & 0.739 & 0.263 \\
\hline Higher & 0.793 & 1.485 & 0.739 & 0.257 \\
\hline Lower & 0.827 & 1.460 & 0.696 & 0.184 \\
\hline Mean & 0.818 & 1.523 & 0.696 & 0.171 \\
\hline \multicolumn{5}{|c|}{ Patients without anti-HBV treatment and ALT level <2x ULN $(\mathrm{N}=79)$} \\
\hline Location A & 0.789 & 1.415 & 0.706 & 0.258 \\
\hline Location B & 0.761 & 1.460 & 0.647 & 0.274 \\
\hline Higher & 0.764 & 1.520 & 0.647 & 0.258 \\
\hline Lower & 0.793 & 1.460 & 0.647 & 0.177 \\
\hline Mean & 0.775 & 1.523 & 0.647 & 0.177 \\
\hline \multicolumn{5}{|c|}{ Patients with anti-HBV treatment $(\mathrm{N}=34)$} \\
\hline Location A & 0.754 & 1.495 & 0.571 & 0.200 \\
\hline Location B & 0.786 & 1.480 & 0.786 & 0.150 \\
\hline Higher & 0.823 & 1.515 & 0.768 & 0.200 \\
\hline Lower & 0.737 & 1.490 & 0.571 & 0.100 \\
\hline Mean & 0.796 & 1.420 & 0.786 & 0.250 \\
\hline
\end{tabular}

\subsection{Correlation of Histological Metavir Scores with Mean ARFI Value}

The mean ARFI value increased with the progression of the histological Metavir scoring system in both treatment and non-treatment groups. A significant correlation was found between the two variables in the non-treatment group (Spearman's rho correlation coefficients $0.597, p<0.001$ ) and in the treatment group (Spearman's rho correlation coefficients 0.587, $p<0.001$, Figure 3). 


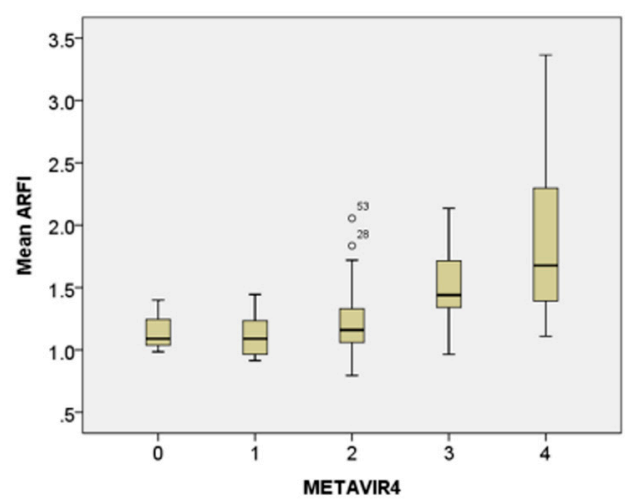

(a)

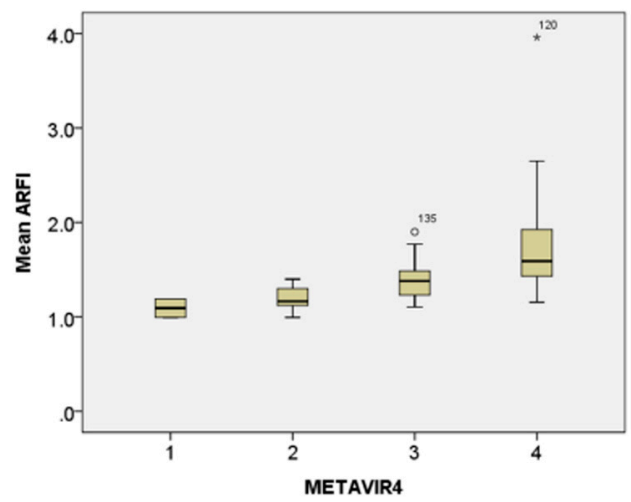

(b)

Figure 3. Mean ARFI values of each METAVIR fibrosis score. A significant correlation was found between mean ARFI values with Metavir grading in the non-treatment group ((a) Sperman's rho correlation coefficients $0.597, p<0.001)$ and treatment group $((\mathbf{b})$ Sperman's rho correlation coefficients $0.587, p<0.001)$.

\subsection{Correlation of ARFI with FibroScan}

Twenty-seven patients had undergone both ARFI and FibroScan studies. All of these patients did not receive anti-HBV therapy at the time of elastography study. The correlation of mean ARFI with FibroScan is quite high. The Pearson correlation is 0.794 with a $p$-value $<0.001$ (Figure 4).

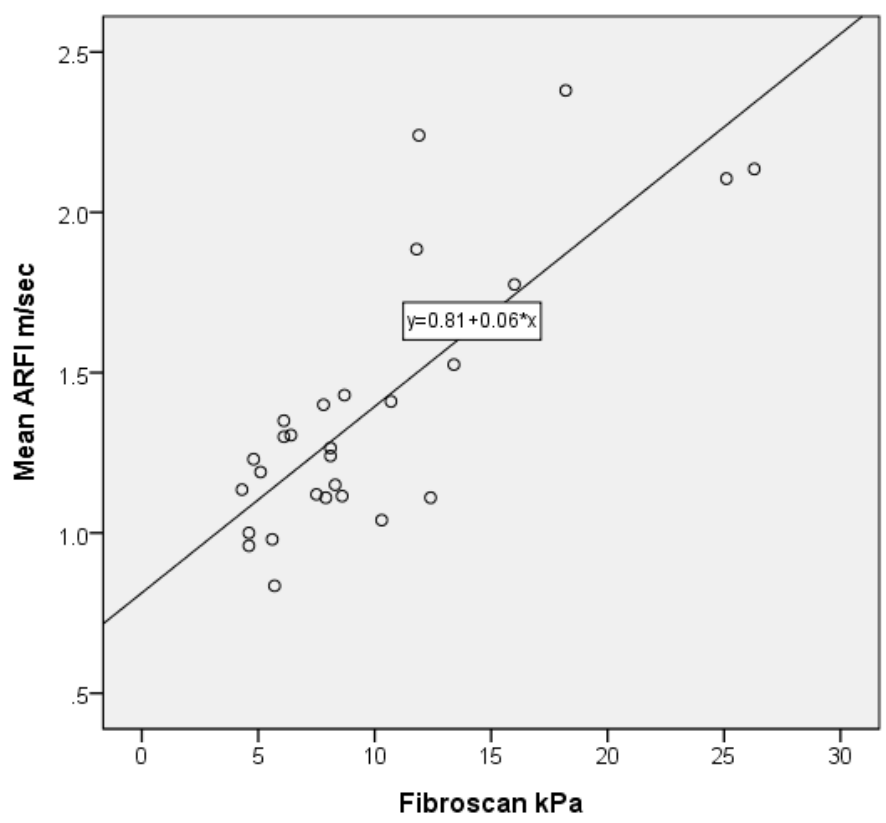

Figure 4. Correlation of Mean ARFI with FibroScan in 27 cases without anti-HBV therapy. The Pearson correlation is 0.794 with a $p<0.001$ (2-tailed).

\subsection{Correlation of ARFI Values with Metavir Score and Treatment Duration}

In the treatment group (Table 3), 19 of the 34 patients (55.9\%) received segmentectomy for hepatocellular carcinoma (HCC). All of them had been receiving anti-HBV therapy at the time of histology analysis and ARFI study. Twenty-two patients (64.7\%) received Entecavir, eight (23.5\%) received Tenofovir, two $(5.9 \%)$ received Telbivudine, one $(2.9 \%)$ received pegylated interferon $2 \mathrm{a}$, and one $(2.9 \%)$ received Adefovir/Telbivudine combination therapy. 
The mean ARFI was negatively correlated with treatment duration (Spearman's rho correlation coefficients $-0.428, p<0.012$ ). According to our unpublished experiences for those patients with chronic hepatitis B with an ALT level lower than $180 \mathrm{IU} / \mathrm{L}$, the cut-off values for prediction of Metavir fibrosis scores $0,1,2,3,4$ are 1.105, 1.218, 1.343, and $1.478 \mathrm{~m} / \mathrm{sec}$, respectively. When ARFI predicted that Metavir fibrosis scores were correlated with histology Metavoir score and duration of therapy, the ARFI value tended to be equal $(3 / 5,60 \%)$ or higher $(2 / 5,40 \%)$ than the corresponding Metavir score for treatment duration within 12 months, equal between 13 and 31 months $(9 / 12,75 \%)$, and frequently lower $(12 / 17,71.4 \%)$ for treatment duration greater or equal to 32 months $(p=0.0012$, Table 3).

Table 3. Correlation of ARFI, Metavir score, and treatment duration.

\begin{tabular}{|c|c|c|c|c|c|c|c|c|c|c|}
\hline \multirow[b]{2}{*}{ Case } & \multirow[b]{2}{*}{ Age } & \multirow[b]{2}{*}{ Sex } & \multirow[b]{2}{*}{ HCC } & \multirow[b]{2}{*}{ ALT } & \multirow[b]{2}{*}{ Durg } & \multirow[b]{2}{*}{ Treatment } & \multirow[b]{2}{*}{ METAVIR } & \multicolumn{3}{|c|}{ ARFI (m/sec) } \\
\hline & & & & & & & & \# Mean of & * Predicted & ** Compared \\
\hline & & & & & & (Mo) & & $\begin{array}{c}\text { Two } \\
\text { Locations }\end{array}$ & $\begin{array}{l}\text { Metavir } \\
\text { Score }\end{array}$ & $\begin{array}{l}\text { with Histology } \\
\text { Metavir Score }\end{array}$ \\
\hline $\mathrm{T} 1$ & 55.7 & $\mathrm{M}$ & 1 & 48 & ETV & 2 & 2 & 1.17 & 2 & equal \\
\hline $\mathrm{T} 2$ & 48.3 & M & 0 & 335 & Pegasy & 5 & 2 & 1.4 & 3 & higher \\
\hline T3 & 52.8 & M & 0 & 103 & ETV & 6 & 2 & 1.3 & 2 & equal \\
\hline $\mathrm{T} 4$ & 47.3 & M & 0 & 50 & ETV & 12 & 3 & 1.5 & 4 & higher \\
\hline $\mathrm{T} 5$ & 30.2 & M & 0 & 46 & ETV & 12 & 4 & 1.84 & 4 & equal \\
\hline T6 & 50.3 & M & 0 & 100 & TDF & 13 & 3 & 1.41 & 3 & equal \\
\hline $\mathrm{T} 7$ & 45.2 & M & 0 & 39 & ETV & 14 & 4 & 1.59 & 4 & equal \\
\hline $\mathrm{T} 8$ & 71.3 & $\mathrm{~F}$ & 0 & 172 & ETV & 18 & 4 & 3.96 & 4 & equal \\
\hline T9 & 52.1 & M & 0 & 23 & ETV & 19 & 3 & 1.77 & 4 & higher \\
\hline T10 & 64.1 & $\mathrm{~F}$ & 1 & 23 & ETV & 21 & 3 & 1.38 & 3 & equal \\
\hline $\mathrm{T} 11$ & 55.3 & M & 1 & 45 & ETV & 22 & 4 & 1.73 & 4 & equal \\
\hline T12 & 53.0 & M & 1 & 19 & ADVTBV & 26 & 4 & 1.59 & 4 & equal \\
\hline $\mathrm{T} 13$ & 57.1 & M & 1 & 42 & ETV & 28 & 3 & 1.15 & 1 & lower \\
\hline T14 & 60.9 & M & 1 & 16 & ETV & 29 & 4 & 1.93 & 4 & equal \\
\hline $\mathrm{T} 15$ & 65.6 & $\mathrm{~F}$ & 0 & 10 & ETV & 31 & 3 & 1.49 & 4 & higher \\
\hline $\mathrm{T} 16$ & 64.0 & $\mathrm{~F}$ & 1 & 27 & TDF & 31 & 4 & 2.65 & 4 & equal \\
\hline T17 & 45.9 & M & 0 & 26 & ETV & 31 & 4 & 2.12 & 4 & equal \\
\hline $\mathrm{T} 18$ & 51.5 & M & 1 & 26 & ETV & 32 & 3 & 1.29 & 3 & lower \\
\hline T19 & 41.3 & M & 1 & 26 & ETV & 32 & 4 & 1.43 & 2 & lower \\
\hline $\mathrm{T} 20$ & 49.3 & M & 0 & 35 & TDF & 36 & 3 & 1.47 & 1 & lower \\
\hline $\mathrm{T} 21$ & 68.4 & $\mathrm{~F}$ & 1 & 19 & TDF & 36 & 4 & 1.16 & 2 & lower \\
\hline $\mathrm{T} 22$ & 45.4 & M & 1 & 45 & TDF & 36 & 3 & 1.29 & 3 & equal \\
\hline $\mathrm{T} 23$ & 45.0 & M & 0 & 316 & TDF & 37 & 4 & 1.9 & 4 & equal \\
\hline $\mathrm{T} 24$ & 68.1 & M & 0 & 16 & ETV & 39 & 1 & 0.995 & 0 & lower \\
\hline $\mathrm{T} 25$ & 59.7 & M & 0 & 34 & TDF & 39 & 3 & 1.36 & 3 & equal \\
\hline $\mathrm{T} 26$ & 42.0 & M & 0 & 19 & ETV & 41 & 3 & 1.105 & 1 & lower \\
\hline $\mathrm{T} 27$ & 60.3 & M & 1 & 50 & TDF & 44 & 2 & 1.12 & 1 & lower \\
\hline $\mathrm{T} 28$ & 63.0 & $\mathrm{~F}$ & 1 & 16 & TBV & 48 & 2 & 0.995 & 0 & lower \\
\hline $\mathrm{T} 29$ & 73.9 & $\mathrm{M}$ & 1 & 13 & TBV & 52 & 4 & 1.52 & 4 & equal \\
\hline T30 & 62.7 & M & 1 & 26 & ETV & 55 & 3 & 1.23 & 2 & lower \\
\hline T31 & 38.5 & $\mathrm{M}$ & 1 & 26 & ETV & 58 & 4 & 1.18 & 1 & lower \\
\hline T32 & 50.4 & $\mathrm{M}$ & 1 & 24 & ETV & 60 & 1 & 1.19 & 1 & equal \\
\hline T33 & 63.7 & M & 1 & 21 & ETV & 68 & 3 & 1.115 & 1 & lower \\
\hline T34 & 69.5 & M & 1 & 68 & ETV & 71 & 4 & 1.435 & 3 & lower \\
\hline
\end{tabular}

T8: possible hypoglycemic agent related toxic hepatitis; T23: poor compliance. Abbreviation: ADV (adefovir); ETV (entecavir); TBV (telbivudine); TDF (tenofovir); \# Spearman's rho correlation coefficients $-0.428, p<0.012 .{ }^{*}$ The cut-off values for prediction of Metavir fibrosis scores $0,1,2,3,4$ are $1.105,1.218,1.343,1.478 \mathrm{~m} / \mathrm{sec}$, respectively. ** Chi-square test of goodness of fit and independence $p=0.0012$.

\section{Conclusions}

We collected a series of 146 patients with chronic hepatitis B who underwent liver needle biopsy $(50.9 \%)$ or surgery for tumor resection $(49.1 \%$ Table 1$)$. Thirty-four $(23.3 \%)$ patients had received anti-HBV therapy at the time of liver histology and ARFI analysis. The AUROC for mean ARFI (0.796, Figure 2) to detect liver cirrhosis (Metavir F4) in anti-HBV treated patients. When the cut-off of the mean ARFI was set to $1.420 \mathrm{~m} / \mathrm{sec}$, the sensitivity was 0.786 and the specificity was 0.750 (Table 2). To the best of our knowledge, the correlation between histology and ARFI in patients receiving anti-HBV treatment was quite rare and was generally in HIV/HBV dual-infected patients [29,30]. 
The main reason for this lower ARFI cut-off level was the suppression of liver inflammation by anti-HBV therapy [31,32]. ARFIs and FibroScans measure liver stiffness by shear-wave velocity. Both of them are greatly influenced by inflammation [33,34]. This is especially a problem in patients with chronic hepatitis B [16]. The inflammatory activity in chronic hepatitis B is not constant and is characterized by intermittent acute exacerbation [35]. There is additional problem in this study: we included patients with hepatocellular carcinoma. ARFI may miss a tumor area according to imaging that is more suitable than the FibroScan in the present study.

We correlated ARFI with Metavir score over different durations of treatment. The values of ARFI tended to be higher than those of histology when the duration of treatment was shorter than or equal to 12 months (Table 3). This could have been because inflammation was not completely suppressed. The ARFI was correlated rather well with the Metavir score between 12 and 31 months after treatment. At this period, the inflammation was suppressed to a minimal level, as evidenced by a low ALT level in most cases. Therefore, the optimal timing for ARFI to measure liver fibrosis will be the second year of nucleos(t)ide analogues therapy. After that, the ARFI level tended to be lower than the histological fibrosis grading. These biases were not related to the small liver sample. Most of the mismatches between ARFI and histology were patients of HCC. These findings indicated that a decrease in liver stiffness identified by ARFI precedes the morphological changes of fibrosis. These observations also confirm that the improvement in liver stiffness at the initial stage is mainly due to reduced necroinflammation [36].

In the non-treatment group, the AUROC of lower ARFI was 0.827 (Figure 1), which was better than that in our previous study (lower ARFI AUROC: 0.707) [16]. Both studies used two-location measurements. This difference may be related to a lower level of inflammation in the current study than in the previous study. The previous study enrolled patients with chronic hepatitis B who intended to receive anti-HBV therapy. In this study, most of the patients were HCC who were hospitalized for surgical resection. The ALT level was lower in this study than in the previous study (91.90 IU/L vs. 117.19 IU/L). The other major difference was that a single operator performed most of the measurements in this study, while the previous study was conducted by several hepatologists. We believe that it is essential to measure ARFI using a standardized protocol and to limit the operator to one or two well-trained, full-time technicians. These measures may decrease the variation and make the data more reliable. In 27 patients in this series, both Fibrosan and ARFI two-location measurements are employed. The correlation is quite good (Figure 4; Pearson correlation: 0.794).

For those patients without anti-HBV therapy, a simple way to reduce the influence of inflammation is to exclude patients with a high ALT level. After excluding those with an ALT level greater than 5x ULN, we found that the cut-off value for diagnosis of liver cirrhosis was similar to that of the entire series (Table 2). However, the sensitivity and specificity are improved. Further reduction or ALT level to $2 x$ ULN did not improve the sensitivity or the specificity. It is our limitation that ALT is a somewhat indirect marker of liver inflammation. Other serological markers of liver inflammation could potentially help to select patients for ARFI studies.

We excluded patients with advance cirrhosis. Our cut-off value was lower than most of the studies in Western countries $[9,10,22]$. However, the cut-off value is similar to reports from Korea [37] and China with low ALT levels [38]. Therefore, we set the mean ARFI cut-off value for liver cirrhosis to be $1.523 \mathrm{~m} / \mathrm{sec}$ for the non-treatment group. For patients receiving anti-HBV therapy, the cut-off value will be lower than untreated patients and is treatment duration dependence.

The other limitation of our study is that we did not have enough cases to present longitudinal results. We only collected ARFI data before and during various durations of anti-viral treatment in our patients. We will evaluate the long-term result after a suitable number of cases have been collected.

We conclude that ARFI is a reliable tool for the measurement of liver fibrosis in chronic hepatitis $B$ with low inflammation status. For those patients with active inflammation, the optimal timing for ARFI analysis will be within the second year of nucleos(t)ide analogue therapy. 
Acknowledgments: This study was funded in full by Chang Gung Memorial Hospital, grant number CMRPG3F0331 and CMRPG3E1121.

Author Contributions: Study concept and design: D.-I.T.; acquisition of data: T.-H.H.; participation in patient management and data collection: T.-H.H., M.-C.Y., W.-C.L., P.-H.T., Y.-C.C., and C.-Y.L.; histology reading: S.-F.H.; statistical analysis, interpretation of data, and drafting of the manuscript: D.-I.T. and C.-H.L.; critical review of the manuscript: Y.-L.W. All authors reviewed the paper and approved the final version.

Conflicts of Interest: The authors have no financial or personal relationships with other people or organizations that could have inappropriately influenced their work.

$\begin{array}{ll}\text { Abbreviations } \\ \text { ARFI } & \text { acoustic radiation force impulse } \\ \text { ALT } & \text { alanine aminotransferase } \\ \text { HCV } & \text { hepatitis C virus } \\ \text { HBV } & \text { hepatitis B virus } \\ \text { HIV } & \text { human immunodeficiency virus } \\ \text { INR } & \text { international normalized ratio } \\ \text { PT } & \text { prothrombin time } \\ \text { FIB4 } & \text { Fibrosis-4 Score } \\ \text { ROC } & \text { receiver-operating characteristic } \\ \text { AUROC } & \text { areas under ROC }\end{array}$

\section{References}

1. Tai, D.I.; Lin, S.M.; Sheen, I.S.; Chu, C.M.; Lin, D.Y.; Liaw, Y.F. Long-term outcome of hepatitis B e antigen-negative hepatitis $B$ surface antigen carriers in relation to changes of alanine aminotransferase levels over time. Hepatology 2009, 49, 1859-1867. [CrossRef] [PubMed]

2. Tai, D.I.; Tsay, P.K.; Chen, W.T.; Chu, C.M.; Liaw, Y.F. Relative Roles of HBsAg seroclearance and mortality in the decline of HBsAg prevalence with increasing age. Am. J. Gastroenterol. 2010, 105, 1102-1109. [CrossRef] [PubMed]

3. Fattovich, G.; Bortolotti, F.; Donato, F. Natural history of chronic hepatitis B: Special emphasis on disease progression and prognostic factors. J. Hepatol. 2008, 48, 335-352. [CrossRef] [PubMed]

4. Liaw, Y.F. Natural history of chronic hepatitis B virus infection and long-term outcome under treatment. Liver Int. 2009, 29, 100-107. [CrossRef] [PubMed]

5. Sebastiani, G.; Gkouvatsos, K.; Pantopoulos, K. Chronic hepatitis C and liver fibrosis. World J. Gastroenterol. 2014, 20, 11033-11053. [CrossRef] [PubMed]

6. Bravo, A.A.; Sheth, S.G.; Chopra, S. Liver biopsy. N. Engl. J. Med. 2001, 344, 495-500. [CrossRef] [PubMed]

7. Regev, A.; Berho, M.; Jeffers, L.J.; Milikowski, C.; Molina, E.G.; Pyrsopoulos, N.T.; Feng, Z.Z.; Reddy, K.R.; Schiff, E.R. Sampling error and intraobserver variation in liver biopsy in patients with chronic HCV infection. Am. J. Gastroenterol. 2002, 97, 2614-2618. [CrossRef] [PubMed]

8. Friedrich-Rust, M.; Ong, M.F.; Martens, S.; Sarrazin, C.; Bojunga, J.; Zeuzem, S.; Herrmann, E. Performance of transient elastography for the staging of liver fibrosis: A meta-analysis. Gastroenterology 2008, 134, 960-974. [CrossRef] [PubMed]

9. Bota, S.; Herkner, H.; Sporea, I.; Salzl, P.; Sirli, R.; Neghinal, A.M.; Peck-Radosavljevic, M. Meta-analysis: ARFI elastography versus transient elastography for the evaluation of liver fibrosis. Liver Int. 2013, 33, 1138-1147. [CrossRef] [PubMed]

10. Kircheis, G.; Sagir, A.; Vogt, C.; Vom Dahl, S.; Kubitz, R.; Häussinger, D. Evaluation of acoustic radiation force impulse imaging for determination of liver stiffness using transient elastography as a reference. World J. Gastroenterol. 2012, 18, 1077-1084. [CrossRef] [PubMed]

11. Lee, S.; Kim, D.Y. Non-invasive diagnosis of hepatitis B virus-related cirrhosis. World J. Gastroenterol. 2014, 20, 445-459. [CrossRef] [PubMed]

12. Crespo, G.; Fernández-Varo, G.; Mariño, Z.; Casals, G.; Miquel, R.; Martinez, S.M.; Gilabert, R.; Forns, X.; Jimenez, W.; Navasa, M. ARFI, FibroScan, ELF, and their combinations in the assessment of liver fibrosis: A prospective study. J. Hepatol. 2012, 57, 281-287. [CrossRef] [PubMed] 
13. Tapper, E.B.; Afdhal, N.H. Vibration-controlled transient elastography: A practical approach to the noninvasive assessment of liver fibrosis. Curr. Opin. Gastroenterol. 2015, 31, 192-198. [CrossRef] [PubMed]

14. Ferraioli, G.; Filice, C.; Castera, L.; Choi, B.I.; Sporea, I.; Wilson, S.R.; Cosgrove, D.; Dietrich, C.F.; Amy, D.; Bamber, J.C.; et al. WFUMB guidelines and recommendations for clinical use of ultrasound elastography Part 3: Liver. Ultrasound Med. Biol. 2015, 41, 1161-1179. [CrossRef] [PubMed]

15. Hu, X.D.; Qiu, L.Y.; Liu, D.; Qian, L.X. Acoustic radiation force impulse elastography for non-invasive evaluation of hepatic fibrosis in chronic hepatitis B and C patients: A systematic review and meta-analysis. Med. Ultrason. 2017, 19, 23-31. [CrossRef] [PubMed]

16. Tai, D.I.; Tsay, P.K.; Jeng, W.J.; Weng, C.C.; Huang, S.F.; Huang, C.H.; Lin, S.M.; Chiu, C.T.; Chen, W.T.; Wan, Y.L. Differences in liver fibrosis between patients with chronic hepatitis B and C: Evaluation by acoustic radiation force impulse measurements at 2 locations. J. Ultrasound Med. 2015, 34, 813-821. [CrossRef] [PubMed]

17. Chen, S.H.; Li, Y.F.; Lai, H.C.; Kao, J.T.; Peng, C.Y.; Chuang, P.H.; Su, W.P.; Chiang, I.P. Effects of patient factors on noninvasive liver stiffness measurement using acoustic radiation force impulse elastography in patients with chronic hepatitis C. BMC Gastroenterol. 2012, 12, 105. [CrossRef] [PubMed]

18. Bota, S.; Sporea, I.; Sirli, R.; Popescu, A.; Danila, M.; Costachescu, D. Intra- and interoperator reproducibility of acoustic radiation force impulse (ARFI) elastography-preliminary results. Ultrasound Med. Biol. 2012, 38, 1103-1108. [CrossRef] [PubMed]

19. Piscaglia, F.; Salvatore, V.; Di Donato, R.; D’Onofrio, M.; Gualandi, S.; Gallotti, A.; Sagrini, E. Accuracy of VirtualTouch Acoustic Radiation Force Impulse (ARFI) imaging for theet al diagnosis of cirrhosis during liver ultrasonography. Ultraschall Med. Eur. J. Ultrasound 2011, 32, 167-175. [CrossRef] [PubMed]

20. Liu, K.; Bui, K.T.; Corte, C.; Lee, A.; Ngu, M.C.; Pattullo, V. Longer duration of transient elastography predicts unreliable liver stiffness measurements. Eur. J. Gastroenterol. Hepatol. 2015, 27, 655-659. [CrossRef] [PubMed]

21. Wong, V.W.; Lampertico, P.; de Lédinghen, V.; Chang, P.E.; Kim, S.U.; Chen, Y.P.; Chan, H.L.Y.; Mangia, G.; Foucher, J.; Chow, W.C.; et al. Probability-based interpretation of liver stiffness measurement in untreated chronic hepatitis B patients. Dig. Dis. Sci. 2015, 60, 1448-1456. [CrossRef] [PubMed]

22. Song, P.; Mellema, D.C.; Sheedy, S.P.; Meixner, D.D.; Karshen, R.M.; Urban, M.W.; Manduca, A.; Sanchez, W.; Callstrom, M.R.; Greenleaf, J.F.; et al. Performance of 2-Dimensional Ultrasound Shear Wave Elastography in Liver Fibrosis Detection Using Magnetic Resonance Elastography as the Reference Standard: A Pilot Study. J. Ultrasound Med. 2016, 35, 401-412. [CrossRef] [PubMed]

23. Wai, C.T.; Greenson, J.K.; Fontana, R.J.; Kalbfleisch, J.D.; Marrero, J.A.; Conjeevaram, H.S.; Lok, A.S.F. A simple noninvasive index can predict both significant fibrosis and cirrhosis in patients with chronic hepatitis C. Hepatology 2003, 38, 518-526. [CrossRef] [PubMed]

24. Vallet-Pichard, A.; Mallet, V.; Nalpas, B.; Verkarre, V.; Nalpas, A.; Dhalluin-Venier, V.; Fontaine, H.; Pol, S. FIB-4: An inexpensive and accurate marker of fibrosis in HCV infection. Comparison with liver biopsy and fibrotest. Hepatology 2007, 46, 32-36. [CrossRef] [PubMed]

25. Bedossa, P.; Poynard, T. An algorithm for the grading of activity in chronic hepatitis C: The METAVIR Cooperative Study Group. Hepatology 1996, 24, 289-393. [CrossRef] [PubMed]

26. Ishak, K.; Baptista, A.; Bianchi, L.; Callea, F.; De Groote, J.; Gudat, F.; Denk, H.; Desmet, V.; Korb, G.; MacSween, R.N.M.; et al. Histological grading and staging of chronic hepatitis. J. Hepatol. 1995, 22, 696-699. [CrossRef]

27. Dietrich, C.F.; Bamber, J.; Berzigotti, A.; Bota, S.; Cantisani, V.; Castera, L.; Cosgrove, D.; Ferraioli, G.; Friedrich-Rust, M.; Gilja, O.H.; et al. EFSUMB Guidelines and Recommendations on the Clinical Use of Liver Ultrasound Elastography, Update 2017 (Long Version). Ultraschall Med. Eur. J. Ultrasound 2017, 38, e16-e47. [CrossRef] [PubMed]

28. Tai, D.I. Reply. Ultrasound Med. 2016, 35, 668. [CrossRef] [PubMed]

29. Miailhes, P.; Pradat, P.; Chevallier, M.; Lacombe, K.; Bailly, F.; Cotte, L.; Trabaud, M.-A.; Boibieux, A.; Bottero, J.; Trepo, C.; et al. Proficiency of transient elastography compared to liver biopsy for the assessment of fibrosis in HIV/HBV-coinfected patients. J. Viral. Hepat. 2011, 18, 61-69. [CrossRef] [PubMed] 
30. Maida, I.; Soriano, V.; Castellares, C.; Ramos, B.; Sotgiu, G.; Martin-Carbonero, L.; Barreiro, P.; Rivas, P.; Fonzalez-Lahoz, J.; Nunez, M. Liver fibrosis in HIV-infected patients with chronic hepatitis B extensively exposed to antiretroviral therapy with anti-HBV activity. HIV Clin. Trials 2006, 7, 246-250. [CrossRef] [PubMed]

31. Lai, C.L.; Shouval, D.; Lok, A.S.; Chang, T.T.; Cheinquer, H.; Goodman, M.D.; Deheertogh, D.; Wilber, R.; Zink, R.C.; Cross, A.; et al. Entecavir versus lamivudine for patients with HBeAg-negative chronic hepatitis B. N. Engl. J. Med. 2006, 354, 1011-1020. [CrossRef] [PubMed]

32. Chang, T.T.; Gish, R.G.; de Man, R.; Gadano, A.; Sollano, J.; Chao, Y.C.; Lok, A.S.; Han, K.H.; Goodman, Z.; Zhu, J.; et al. A comparison of entecavir and lamivudine for HBeAg-positive chronic hepatitis B. N. Engl. J. Med. 2006, 354, 1001-1010. [CrossRef] [PubMed]

33. Viganò, M.; Massironi, S.; Lampertico, P.; Iavarone, M.; Paggi, S.; Pozzi, R.; Conte, D.; Colombo, M. Transient elastography assessment of the liver stiffness dynamics during acute hepatitis B. Eur. J. Gastroenterol. Hepatol. 2010, 22, 180-184. [CrossRef] [PubMed]

34. Verveer, C.; Zondervan, P.E.; ten Kate, F.J.W.; Hansen, B.E.; Janssen, H.L.A. Evaluation of transient elastography for fibrosis assessment compared with large biopsies in chronic hepatitis B and C. Liver Int. 2012, 32, 622-628. [CrossRef] [PubMed]

35. Liaw, Y.F.; Tai, D.I.; Chu, C.M.; Pao, C.C.; Chen, T.J. Acute exacerbation in chronic type B hepatitis: Comparison between HBeAg and antibodypositive patients. Hepatology 1987, 7, 20-23. [CrossRef] [PubMed]

36. Knop, V.; Hoppe, D.; Welzel, T.; Vermehren, J.; Herrmann, E.; Vermehren, A.; Friedrich-Rust, M.; Sarrazin, C.; Zeuzem, S.; Welker, M.-W. Regression of fibrosis and portal hypertension in HCV-associated cirrhosis and sustained virologic response after interferon-free antiviral therapy. J. Viral. Hepat. 2016, 23, 994-1002. [CrossRef] [PubMed]

37. Chung, J.H.; Ahn, H.S.; Kim, S.G.; Lee, Y.N.; Kim, Y.S.; Jeong, S.W.; Jang, J.Y.; Lee, S.H.; Kim, H.S.; Kim, B.S. The usefulness of transient elastography, acoustic-radiation-force impulse elastography, and real-time elastography for the evaluation of liver fibrosis. Clin. Mol. Hepatol. 2013, 19, 156-164. [CrossRef] [PubMed]

38. Zhang, D.; Chen, M.; Wang, R.; Liu, Y.; Zhang, D.; Liu, L.; Zhou, G. Comparison of acoustic radiation force impulse imaging and transient elastography for non-invasive assessment of liver fibrosis in patients with chronic hepatitis B. Ultrasound Med. Biol. 2015, 41, 7-14. [CrossRef] [PubMed]

(C) 2017 by the authors. Licensee MDPI, Basel, Switzerland. This article is an open access article distributed under the terms and conditions of the Creative Commons Attribution (CC BY) license (http:// creativecommons.org/licenses/by/4.0/). 